\title{
Surgical removal of subfoveal choroidal neovascularisation in highly myopic patients
}

José M Ruiz-Moreno, Concepción de la Vega

\begin{abstract}
Aim-To analyse the visual results obtained in the treatment of subretinal choroidal neovascularisation (CNV) in patients with high myopia by vitrectomy and extraction of the neovascular membrane. Methods-22 eyes of 22 patients with high myopia (>-6 dioptres and/or axial length $>26 \mathbf{m m}$ ) with subfoveal CNV treated by extraction of the CNV were analysed retrospectively. The patients' mean age was 60.27 (SD 16.41) years (range 32-83 years). The mean follow up was $29.3(9.9)$ months (range 12-42 months).

Results-Best corrected visual acuity (BCVA) preoperatively was $0.09(0.07)$ (range 0.01-0.3). After treatment BCVA was $0.12(0.10)$ (range $0.01-0.4$ ), a difference without statistical significance $(p=0.03$, Student's $t$ test paired data). In four cases the CNV recurred, in three cases cataract developed that required extraction, and in one case retinal detachment occurred in the early postoperative period. Topical treatment was necessary in two cases to lower the intraocular pressure.

Conclusions-The treatment of subfoveal CNV in highly myopic patients by surgical removal by vitrectomy does not achieve any significant improvement of the BCVA. (Br f Ophthalmol 2001;85:1041-1043)
\end{abstract}

José M Ruiz-Moreno,

División de Oftalmología,

Universidad Miguel

Hernández, Campus de San
Juan, 03550, Alicante, Spain

jm.ruiz@umh.es

Accepted for publication 27 March 2001

High myopia (more than -6 dioptres and/or longer than $26 \mathrm{~mm}$ of axial length), is the seventh most common cause of legal blindness in adults in the USA. ${ }^{1}$ It is present in $0.5 \%$ of the

Table 1 Characteristics of myopic patients with $C N V$

\begin{tabular}{llllllll}
\hline $\begin{array}{l}\text { Patient } \\
\text { No }\end{array}$ & $\begin{array}{l}\text { Age } \\
\text { (years) }\end{array}$ & Sex & Eye & $\begin{array}{l}\text { Initial } \\
\text { BCVA }\end{array}$ & $\begin{array}{l}\text { Final } \\
\text { BCVA }\end{array}$ & $\begin{array}{l}\text { Follow up } \\
\text { (months) }\end{array}$ & Complications \\
\hline 1 & 69 & Female & Right & 0,03 & 0,02 & 29 & RD \\
2 & 66 & Male & Right & 0,16 & 0,04 & 24 & Cataract \\
3 & 34 & Male & Right & 0,05 & 0,1 & 37 & \\
4 & 41 & Male & Right & 0,05 & 0,16 & 41 & Recurrent CNV \\
5 & 70 & Female & Right & 0,05 & 0,3 & 31 & Glaucoma \\
6 & 52 & Male & Left & 0,1 & 0,16 & 37 & \\
7 & 74 & Male & Left & 0,3 & 0,3 & 30 & \\
8 & 83 & Male & Right & 0,1 & 0,2 & 12 & Recurrent CNV \\
9 & 78 & Female & Right & 0,04 & 0,03 & 20 & Recurrent CNV \\
10 & 38 & Male & Right & 0,16 & 0,4 & 13 & Recurrent CNV \\
11 & 50 & Male & Right & 0,1 & 0,1 & 28 & \\
12 & 47 & Male & Left & 0,1 & 0,16 & 26 & \\
13 & 71 & Female & Left & 0,03 & 0,03 & 26 & Cataract \\
14 & 58 & Female & Right & 0,2 & 0,1 & 26 & \\
15 & 82 & Male & Left & 0,01 & 0,01 & 32 & \\
16 & 74 & Male & Right & 0,2 & 0,16 & 39 & \\
17 & 61 & Female & Right & 0,1 & 0,1 & 35 & \\
18 & 70 & Male & Right & 0,02 & 0,03 & 32 & Cataract \\
19 & 76 & Male & Left & 0,03 & 0,02 & 42 & \\
20 & 64 & Female & Left & 0,04 & 0,04 & 35 & \\
21 & 32 & Female & Right & 0,01 & 0,1 & 27 & \\
22 & 36 & Male & Left & 0,1 & 0,1 & 24 & \\
\hline
\end{tabular}

$\mathrm{BCVA}=$ best corrected visual acuity. $\mathrm{RD}=$ retinal detachment.
European population ${ }^{2}$ and it is estimated to represent $2 \%$ of all types of myopia. ${ }^{3}$

The excessive elongation of the anteriorposterior axis of the eye is associated with complications ${ }^{4}$ such as choroidal neovascularisation (CNV), frequently with ruptures of Bruch's membrane, ${ }^{5}$ that appear in $4.3 \%$ of the patients with high myopia.

CNV varies from $4 \%$ to $11 \%$ of highly myopic patients. ${ }^{7}$ Its presence is confirmed by fluorescein angiography, demonstrating the typical pattern of neovascular membranes.

One proposed therapy is macular surgery with removal of the CNV. ${ }^{8}$ We present in this paper the results obtained in the retrospective review of a consecutive series of patients with high myopia and subfoveal CNV following such surgery.

\section{Patients and methods}

For this study we have retrospectively reviewed 22 eyes of 22 consecutive patients with high myopia, in which subfoveal CNV was diagnosed, being treated by vitrectomy and surgical removal of the CNV.

As criteria of high myopia we used the existence of a refractive error greater than -6 dioptres and/or an axial length greater than $26 \mathrm{~mm}$.

Selection criteria:

- Preoperative best corrected visual acuity (BCVA) less than or equal to 0.3 (decimal scale). A progressive loss of BCVA during two consecutive examinations was documented and the decline in acuity was believed to be due to the growth of the CNV

- No other ocular pathologies associated with high myopia

- No previous treatment by laser in the foveal avascular zone

- Clinical evidence of CNV, confirmed by fluorescein angiography

- Informed written consent

- All patients with clinical signs of age related macular degeneration (ARMD), such as soft drusen, presumed ocular histoplasmosis syndrome (POHS), as well as other pathologies that may develop $\mathrm{CNV}$ in their evolution, were excluded.

The average age of the patients was 60.27 (SD 16.41) years (range 32-83 years), of which nine were female and 13 male. In 14 patients the right eye was operated on and in eight patients the left. The average follow up was 29.3 (7.9) months (range 12-42 months).

The surgical technique was performed as described previously ${ }^{10}$ under local anaesthesia and as outpatients.

Face down positioning during the first 24 hours after surgery was maintained and topical medication begun with steroids and antibiotics. 
Table 2 Postoperative evolution of best corrected visual acuity

\begin{tabular}{llllll}
\hline Follow up & Average & $\begin{array}{l}\text { Standard } \\
\text { deviation }\end{array}$ & Minimum. & Maximum & No \\
\hline 2 months & 0.10 & 0.09 & 0.01 & 0.4 & 22 \\
8 months & 0.11 & 0.10 & 0.01 & 0.4 & 22 \\
14 months & 0.09 & 0.08 & 0.01 & 0.3 & 20 \\
20 months & 0.09 & 0.07 & 0.01 & 0.3 & 20 \\
26 months & 0.1 & 0.1 & 0.01 & 0.3 & 17 \\
\hline
\end{tabular}

\section{Results}

We analysed the results of 22 patients with high myopia who underwent surgery for removal of subfoveolar CNV (Table 1). The mean BCVA before surgery was 0.09 (0.07) (range 0.01$0.3)$; at the end of the follow up period the mean BCVA was $0.12(0.1)$ (range 0.01-0.4), the difference not being statistically significant ( $\mathrm{p}=0.113$, Student's $t$ test paired data).

If we study the evolution of BCVA after surgery we find that the average BCVA from 2 months postoperatively until 26 months does not decrease with time ( $\mathrm{p}>0.05$; Anova test, Table 2).

We found an improvement of BCVA after surgery in nine $(40.9 \%)$ patients, a worsening in six $(27.3 \%)$, and no variation in another seven $(31.8 \%)$.

CNV recurred in four patients who were treated by green argon laser photocoagulation.

Of the 22 patients three developed cataracts which required surgery, and in one patient retinal detachment appeared 3 months after surgery. This patient was operated on with scleral buckling without further complications. We needed to use chronic topical medication to control the intraocular pressure in two cases.

\section{Discussion}

High myopia is the first aetiological cause of CNV in young people. ${ }^{11}$ In a study of 308 eyes from 202 patients with high myopia, CNV appeared in $5.2 \%$ of the eyes. ${ }^{12}$ The natural evolution of CNV in high myopia is very poor final visual acuity. ${ }^{13} 14$

One of the possible treatments of extrafoveolar and juxtafoveolar $\mathrm{CNV}$ is direct laser photocoagulation. In high myopia a progressive growth of the scar after photocoagulation has been described, without relation to the wavelength of the laser, the axial length of the eye, or to other factors. ${ }^{15}$ Comparing this it has been noticed that the growth of the scar following $\mathrm{CNV}$ photocoagulation in ARMD was $28.7 \%$, while in high myopia it was $109.2 \% .^{16}$

Avila $^{17}$ affirms that the results in patients treated with laser cannot be distinguished from patients without treatment, finding a drop in visual acuity in $57 \%$ in those treated and in $46 \%$ of those not treated. It is difficult to compare the results of this study with others carried out, but it is certainly clear that natural evolution and the results of laser treatment of the subfoveolar $\mathrm{CNV}$ in myopic eyes giving very poor visual acuity. ${ }^{9}$

One of the therapeutic alternatives was surgery to extract the CNV. At the present time two new treatment possibilities include macular translocation and photodynamic therapy.
The majority of the reports regarding submacular surgery are related to the $\mathrm{CNV}$ associated with ARMD or to POHS. Adelberg ${ }^{9}$ published a paper about the surgical extraction of CNV in 17 eyes, five of which were highly myopic. The visual acuity after surgery improved in two of the five eyes, with recurrence in one.

For Thomas, ${ }^{18}$ the result in 10 eyes after surgical removal of CNV in myopic patients, is a lessening of visual acuity, this being 0.2 or lower in all eyes and with a recurrent CNV in two of the 10 eyes. In another later paper, of 23 eyes, eight $(35 \%)$ had a final visual acuity of $20 / 40$ or better, five $(22 \%)$ between $20 / 50$ and 20/100, and 10 (43\%) between 20/200 and 20/400. ${ }^{19}$ Other authors have described positive results from surgery with improvement in $45 \%$ of eyes and no change in $37 \% .^{20}$

The 22 patients selected for this paper represent a group of patients with high myopia who developed CNV as a result of the degenerative processes associated with their ocular disease.

We found an improvement of BCVA in nine $(40.9 \%)$ of the 22 patients studied. We observed no variation in seven $(31.8 \%)$, and a deterioration in six $(27.2 \%)$. The difference between the preoperative (0.09) (0.07) and postoperative (0.12) (0.10) BCVA was not statistically significant $(\mathrm{p}=0.03$, Student's $t$ test paired data).

In our patients the BCVA did not decrease with time (Table 2), whereas the visual results obtained after treatment of myopic CNV with photocoagulation did. ${ }^{15}$

In four cases the CNV recurred, three cases developed cataracts requiring surgery and in one case retinal detachment occurred.

In our series in only one patient was the final BCVA 0.4, compared with other results. It is probably due to the average age (60 years) and the inclusion criterion of waiting for two consecutive examinations to confirm progressive loss of vision, that may have allowed the CNV to disrupt the retinal pigmentary epithelium (RPE).

It is not known why in some eyes the visual prognosis worsens and in others it improves after surgery, probably being related to the amount of RPE extracted. Clinical and laboratory studies suggest that the integrity of RPE and the choriocapillaris is the principal factor which will determine the final prognosis after submacular surgery. ${ }^{9}$

In our experience RPE is compromised in the majority of cases and it is extracted, leaving in some patients a denuded area of Bruch's membrane and a defect in the RPE after surgery. Laboratory studies confirm that these denuded areas induce the progressive secondary atrophy of the choriocapillaris and external layers of the retina. These changes have been investigated in animal research ${ }^{21}$ and are transferable to the phenomena that appear after submacular surgery in our patients. ${ }^{22}$

In conclusion, and in agreement with our results and with previous papers, ${ }^{9}{ }^{18} 19$ surgical removal of the CNV in highly myopic patients stabilises the evolution in some patients 
without inducing a significant improvement in visual acuity. Randomised, prospective studies will be required to evaluate the role of surgical removal of the CNV in highly myopic patients. Comparison of outcomes with other techniques such as macular translocation and photodynamic therapy will also be required in order to determine which is the best treatment for subfoveal $\mathrm{CNV}$ in high myopia.

1 National Society for the Prevention of Blindness. NSPB fact book. Estimated statistics of blindness and vision problems. New book. Estimated statistics

2 Stocker FW. Pathologic anatomy of the myopic eye with regard to newer theories of ethiology and pathogenesis of myopia. Arch Ophthalmol 1943;30:476-88.

3 Michael DD. Visual optics and refraction. A clinical approach. 2nd ed. St Louis: CV Mosby, 1980:1985.

4 Curtin BJ. Physiologic vs pathologic myopia: genetics vs environment. Ophthalmology 1979;86:681-91.

5 Johnson DA, Yannuzzi LA, Shakin JL, et al. Lacquer cracks following laser treatment of choroidal neovascularization in pathologic myopia. Retina 1998;18:118-24.

6 Curtin BJ, Karlin DB. Axial length measurements and fundus changes of the myopic eye. Am f Ophthalmol 1971;71: $42-53$.

7 Curtin BJ. The posterior staphiloma of pathologic myopia Trans Am Ophthalmol Soc 1977;75:68-86.

8 De Juan E Jr, Machemer R. Vitreous surgery for hemorrhagic and fibrous complications of age-related macular degeneration. Am f Ophthalmol 1988;105:25-29.

9 Adelberg DA, Del Priore LV, Kaplan HJ. Surgery for subfoveal membranes in myopia, angioid streaks, and other disorders. Retina 1995;15:198-205.

10 Ruiz-Moreno JM, Pérez-Santonja JJ. Dissection of the posterior hyaloid. Arch Ophthalmol 1998;116:1392-3.
11 Cohen SY, Laroche A, Leguen Y, et al. Etiology of choroidal neovascularization in young patients. Ophthalmology 1996; 03:1241-4.

12 Grossniklaus HE, Green WR. Pathologic findings in pathologic myopia. Retina 1992;12:127-33.

13 Hampton GR, Kohen D, Bird AC. Visual prognosis of disciform degeneration in myopia. Ophthalmology 1983;90: $923-6$

14 Hotchkiss ML, Fine SL. Pathologic myopia and choroidal neovascularization. Am f Ophthalmol 1981;91:177-83.

15 Brancato R, Pece A, Avanza P, et al. Photocoagulation scar expansion after therapy for choroidal neovascularization in degenerative myopia. Retina 1990;10:239-43.

16 Oshima Y, Harino S, Tano Y. Scanning laser ophthalmoscope microperimetric assessment in patients with successful laser treatment for juxtafoveal choroidal neovascularization. Retina 1998;18:109-17.

17 Avila MP, Weiter JJ, Jalkh AE, et al. Natural history of choroidal neovascularization in degenerative myopia. Ophthalmology 1984;91:1573-81.

18 Thomas MA, Dickinson JD, Melberg NS, et al. Visual results after surgical removal of subfoveal choroidal neovascular membranes. Ophthalmology 1994;101:138496

19 Uemura A, Thomas MA. Subretinal surgery for choroidal neovascularization in patients with high myopia. Arch Ophthalmol 2000;118:344-50.

20 Bottoni F, Perego E, Airaghi P, et al. Surgical removal of subfoveal choroidal neovascular membranes in high myopia. Graefes Arch Clin Exp Ophthalmol 1999;237:57382

21 Del Priore LV, Hornbeck R, Kaplan HJ, et al. Debridement of the pig retinal pigment epithelium in vivo. Arch Ophthalmol 1995;113:939-44.

22 Nasir M, Zarbin MA. Choriocapillaris atrophy as a complication of surgical excision of choroidal neovascular membranes. Invest Ophthalmol Vis Sci 1993;34 (suppl): 834 . 